\title{
Optimisation of zinc oxide surge arrester design using gravitational search algorithm and imperialist competitive algorithm
}

\author{
Syahirah Abd Halim¹, Azah Mohamed², Nor Azwan Mohamed Kamari³, Afida Ayob ${ }^{4}$, Ab Halim Abu \\ Bakar $^{5}$, Hazlee Azil Illias ${ }^{6}$ \\ ${ }^{1,2,3,4}$ Centre for Integrated Engineering Systems and Advanced Technologies, Universiti Kebangsaan Malaysia, \\ Selangor, Malaysia \\ ${ }^{5}$ UM Power Energy Dedicated Advanced Centre (UMPEDAC), Wisma R\&D UM, Universiti Malaya, Kuala Lumpur, \\ Malaysia \\ ${ }^{6}$ Department of Electrical Engineering, Faculty of Engineering, Universiti Malaya, Kuala Lumpur, Malaysia
}

\begin{tabular}{l}
\hline Article Info \\
\hline Article history: \\
Received Sep 30, 2018 \\
Revised Nov 27, 2018 \\
Accepted Dec 15, 2018 \\
\hline
\end{tabular}

\section{Keywords:}

Arrester design

Electric field optimization

Finite element analysis

\begin{abstract}
Reducing electric field stress near the energised end of surge arresters is very important because it may increase the lifetime of the highly stressed $\mathrm{ZnO}$ column in vicinity of the high voltage electrode. Most of previous works were based on manufacturers' procedures and trial and error method to improve the surge arrester designs. In this work, optimisation of $\mathrm{ZnO}$ surge arrester design models using Gravitational Search Algorithm (GSA) and Imperialist Competitive Algorithm (ICA) is proposed. The surge arrester models were developed using finite element analysis (FEA) and used to determine the electric field distribution. The optimisation methods were used to determine the arrester design parameters which yield the minimum electric field stress surrounding the energized end of the surge arresters. GSA is less complex since it requires only two parameters to be adjusted i.e. mass and velocity while ICA demonstrates faster convergence and better achievement of global optimum. The performance of the proposed methods was then compared with the manufacturer's test data and previously developed methods.
\end{abstract}

Copyright @ 2019 Institute of Advanced Engineering and Science. All rights reserved.

\section{Corresponding Author:}

Syahirah Abd Halim,

Centre for Integrated Engineering Systems and Advanced Technologies,

Universiti Kebangsaan Malaysia, Selangor, Malaysia.

Email: syahirah_h@ukm.edu.my

\section{INTRODUCTION}

Zinc oxide $(\mathrm{ZnO})$ surge arresters have been widely used nowadays in overvoltage protection of transmission line systems [1]. The most recently developed $\mathrm{ZnO}$ surge arresters do not require serial gaps owing to their excellent nonlinear properties [2]. Nevertheless, the removal of the serial gap causes $\mathrm{ZnO}$ disks being continuously stressed by $\mathrm{AC}$ power frequency voltage [3]. To increase the uniformity of the electric potential distribution, optimisation of the electric field intensity around the surge arrester is needed.

Numerous researches related to determination of electric field in a surge arrester have been published. Han et al. describe the formulation of semi-analytic finite element method to determine potential distribution of high voltage metal oxide arrester [4]. Meanwhile, Haddad \& Naylor computed electric potential and field distribution of a typical polymer zinc oxide surge arrester by means of finite element method [5]. Ekonomou et al. have formulated an artificial neural networks (ANNs) based method which could be useful in determining electric field distribution of medium voltage surge arresters for design processes and diagnostic tests [6]. 
However, most of the studies are just limited for electric field magnitude calculation. Only several studies had presented methods to minimize electric field intensity of surge arresters during normal operating conditions. He et al. discussed their findings on the electric potential distribution of an AC $1000 \mathrm{kV}$ ultra high voltage (UHV) metal oxide surge arrester [3]. The study had focused on analysing and improving the electric potential distribution of the UHV surge arrester by the application of three different approaches; field-circuit combination, three-dimensional (3D) finite element method (FEM) and circuit analysis.

Kumar \& Mogaveera had attempted to improve the voltage distribution uniformity of a $220 \mathrm{kV}$ and a $400 \mathrm{kV}$ surge arresters under clean and polluted environment by means of numerical field computation [7]. In the study, design optimisation of the surge arresters' geometries which include grading ring and spacers was conducted in order to investigate their influence on the voltage distribution under normal operating conditions.

In the past works, the electric field distribution of a surge arrester greatly depends on the geometry design and electrical properties of the governing material. The minimisation of the electric field magnitude of the arrester was achieved by proposing several design methods. However, works on using optimisation methods to minimise the electric field magnitude are less likely to be found in literature.

Therefore, in this work, minimising the electric field magnitude in two $\mathrm{ZnO}$ surge arrester design models is proposed by using Gravitational Search Algorithm (GSA) and Imperialist Competitive Algorithm (ICA). The surge arrester models were developed using finite element analysis (FEA) to determine the electric field distribution. To validate the performance of the proposed method, comparison with the manufacturer's test data and other optimisation methods were made. Using optimisation methods, it is more convenient to perform design optimisation on the surge arrester geometry instead of changing the material properties by trial and error to obtain the desired electric field distribution.

\section{MODELLING OF SURGE ARRESTER IN FEA}

Series of tests were carried out on transmission line arrester having rated voltage of $120 \mathrm{kV}$. Table 1 specifies the characteristics of the surge arrester in this work, as specified in the manufacturer's datasheet. Figure 1 shows the two-dimensional (2D) axial symmetric model geometry of the $\mathrm{ZnO}$ arrester that has been developed in the FEA software. The 'Electrostatic' interface of the AC/DC module available in the software was used to solve the model. A layer of air surrounding the arrester was also drawn to observe the electric field distribution on the surface of the sheds. Material properties as shown in Table 2 were then assigned to each domain.

Table 1. Electrical and Insulation Data for Arrester

\begin{tabular}{lc}
\hline \multicolumn{2}{c}{ Table 1. Electrical and Insulation Data for Arrester } \\
\hline Rated voltage & Parameter \\
Maximum residual voltage $(10 \mathrm{kA} 8 / 20 \mu$ s current $)$ & $120 \mathrm{kV}$ \\
Height & $316 \mathrm{kV}$ \\
Insulation material & $750 \mathrm{~mm}$ \\
Creepage distance & Silicone rubber \\
\hline
\end{tabular}

5

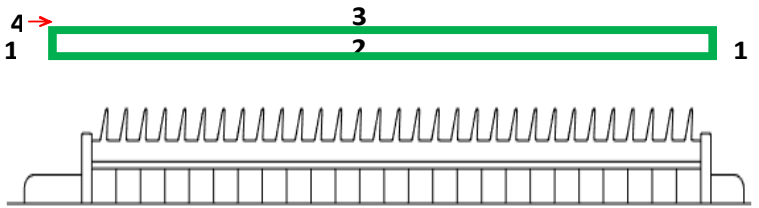

Figure 1. 2D axial symmetrical of $\mathrm{ZnO}$ surge arrester model

Table 2. Material Properties of the Surge Arrester Components

\begin{tabular}{cccc}
\hline Domain & Material & Relative permittivity, $\varepsilon_{r}$ & Conductivity, $\sigma\left(\mathrm{Sm}^{-1}\right)$ \\
\hline 1 & Aluminium & 1 & $3.774 \times 10^{4}$ \\
2 & Zinc oxide & 2250 & Non-linear \\
3 & Silicone rubber & 3.6 & $1 \times 10^{-18}$ \\
4 & Fibreglass & 4.2 & $1 \times 10^{-18}$ \\
5 & Air & 1 & 0 \\
\hline
\end{tabular}


After assigning the material properties, relevant interface conditions were applied at each boundary in the geometry. The ground boundary condition was applied at the bottom part of the arrester, which specifies zero electric potential. The upper part of the arrester was specified as a terminal source of stationary electric potential. Since the arrester was enclosed in a spherical air domain, its outermost boundary condition was assigned as electric insulation. The interface condition of the remaining boundaries was set as continuity. The next step was to mesh the geometry into smaller elements for effective computation. In this model, extremely fine mesh elements were applied on the area surrounding the $\mathrm{ZnO}$ column. This was done to increase the precision of the electric field distribution as the $\mathrm{ZnO}$ column determines the behaviour of the arrester.

\section{DESIGN OPTIMISATION USING ICA AND GSA}

The surge arrester design optimisation procedures used in this work are as follows:

Step 1: The arrester was modelled in FEA software to calculate the electric field distribution.

Step 2: The model was interfaced with GSA and ICA algorithms for design optimisation.

Step 3: The optimisation was repeated until the convergence criteria are reached.

The optimised variables must result in minimum electric field magnitude at regions which are considered critical on the surge arrester. In this case, the maximum electric field on the silicone rubber surface must be equal or less than the electric strength of air, i.e. $3 \mathrm{kVmm}^{-1}$, to avoid any surface discharge occurrence. Thus, the objective function is defined as:

$$
\mathrm{J}=\min \left\{E_{\max }-3 k V m m^{-1}\right\}
$$

where Emax is the maximum electric field (in $\mathrm{kVmm}^{-1}$ ) point along the arrester axis, which is located on the tip of the insulation housing shed near to the high voltage electrode. The constraints defined considering the limits relative to arrester's dimension and material properties are shown in Table 3 . There are no available specific standards related to the surge arrester's design, thus the variation limits of the design parameters were chosen based on the simulation results and the geometric feasibility.

Table 3. Limits Relative to Arrester Dimension and Material Properties

\begin{tabular}{cccc}
\hline Parameter & Lower limit & $\begin{array}{c}120 \mathrm{kV} \text { arrester } \\
\text { Upper limit }\end{array}$ & Intial value \\
\hline Radius of FRP rod & $0.1 \mathrm{~cm}$ & $2.0 \mathrm{~cm}$ & $1.0 \mathrm{~cm}$ \\
Radius of insulation housing & $2.0 \mathrm{~cm}$ & $4.0 \mathrm{~cm}$ & $3.0 \mathrm{~cm}$ \\
Relative permittivity of silicone rubber & 5.0 & 7.0 & 6.0 \\
Relative permittivity of FRP rod & 3.7 & 10.0 & 4.2 \\
\hline
\end{tabular}

\subsection{Gravitational Search Algorithm (GSA)}

Gravitational Search Algorithm involves a group of searcher agents, which interact between them through the gravity force. The agents, also known as objects, are measured in term of performance according to their masses. This gravity force causes movement of the objects towards other objects with heavier masses. The flowchart of the GSA method is depicted in Figure $2[8,9]$.

\subsection{Imperialist Competitive Algorithm (ICA)}

In this algorithm, the population individuals are referred as country. Initially, some of the countries with better objective function are assigned as imperialists while others are assigned as colonies that all together form some empires. During the competition, the power of the dominant empire will increase, and the power of the weak empire will decrease. The suitable empires will take possession of their colonies. At the end of the competition, there will be only one imperialist and others will be its colonies. The flowchart of the ICA method is depicted in Figure 3 [10, 11].

\section{ELECTRIC FIELD DISTRIBUTION IN SURGE ARRESTER}

The electric field distributions in the rated $120 \mathrm{kV}$ surge arrester model geometry when electric potential of $132 \mathrm{kV}$ was applied on the energized end are illustrated in Figure 4 and Figure 5. The cut line 2D plot of the electric field along tip of the housing sheds is illustrated in Figure 6. 


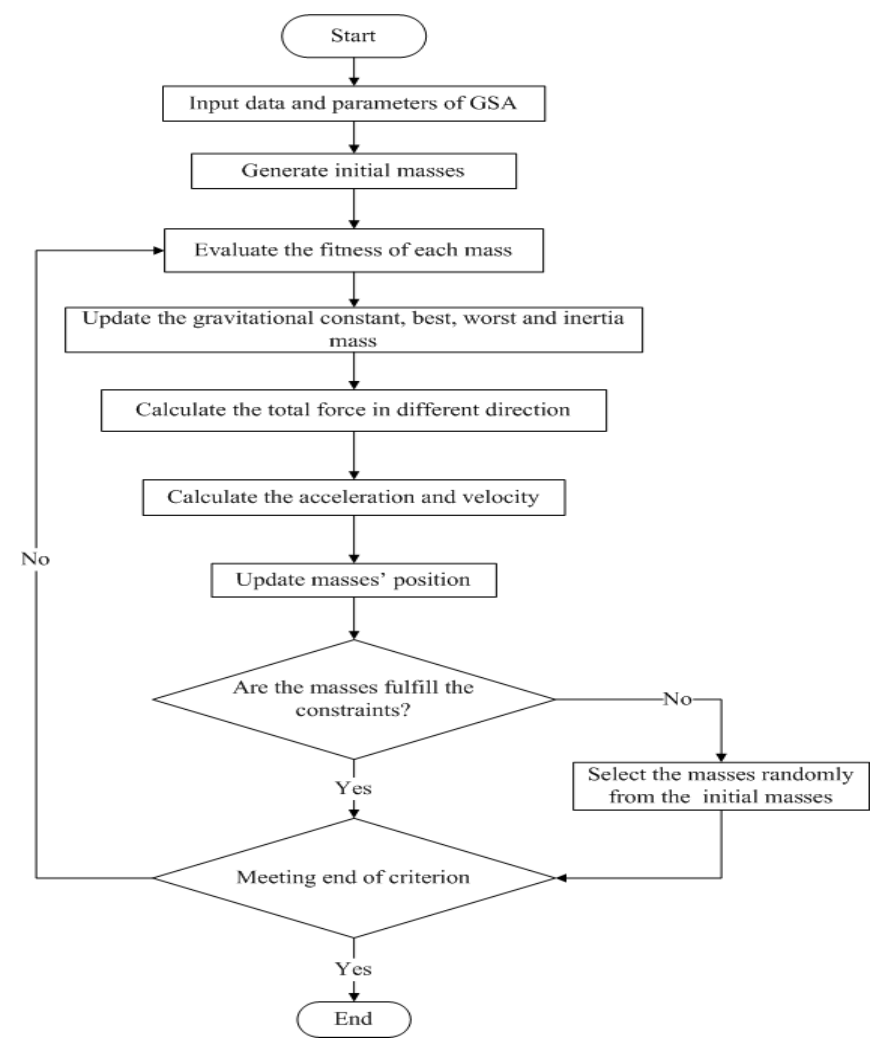

Figure 2. Flowchart of Gravitational Search Algorithm

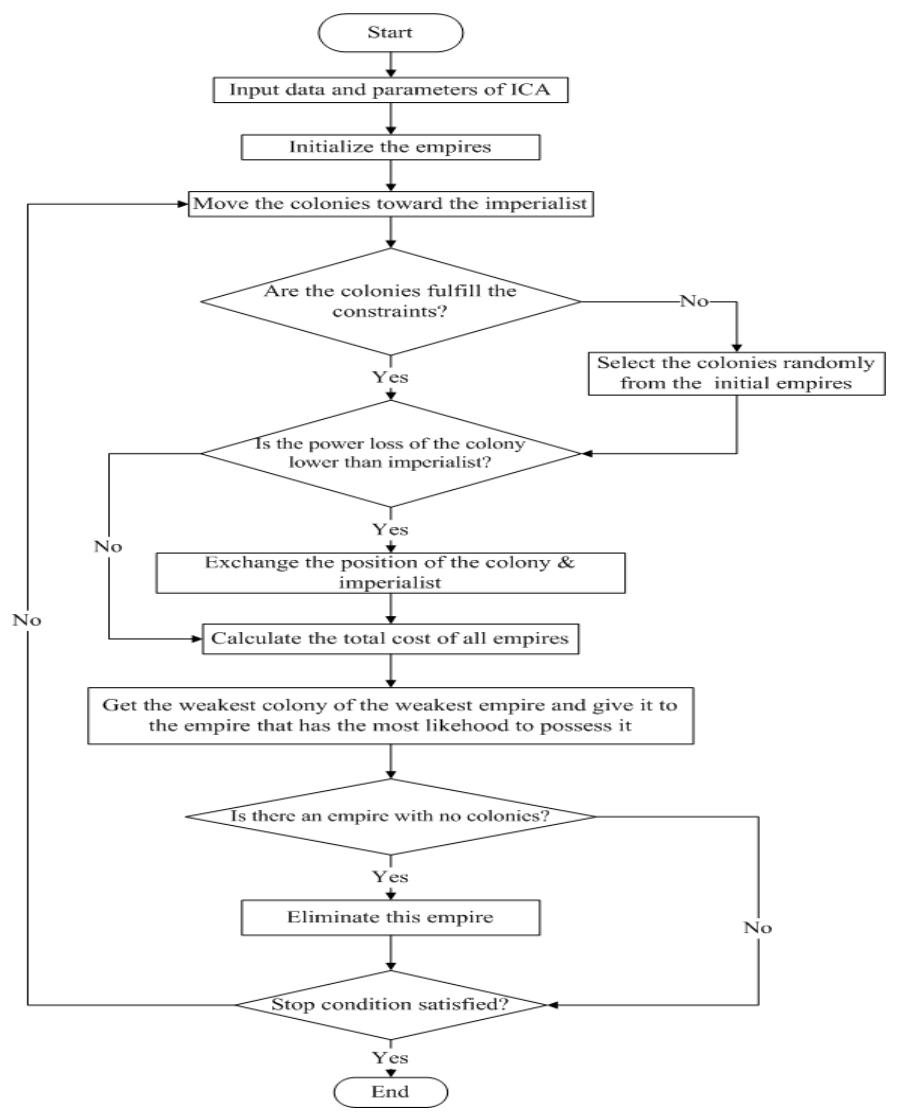

Figure 3. Flowchart of Imperialist Competitive Algorithm 


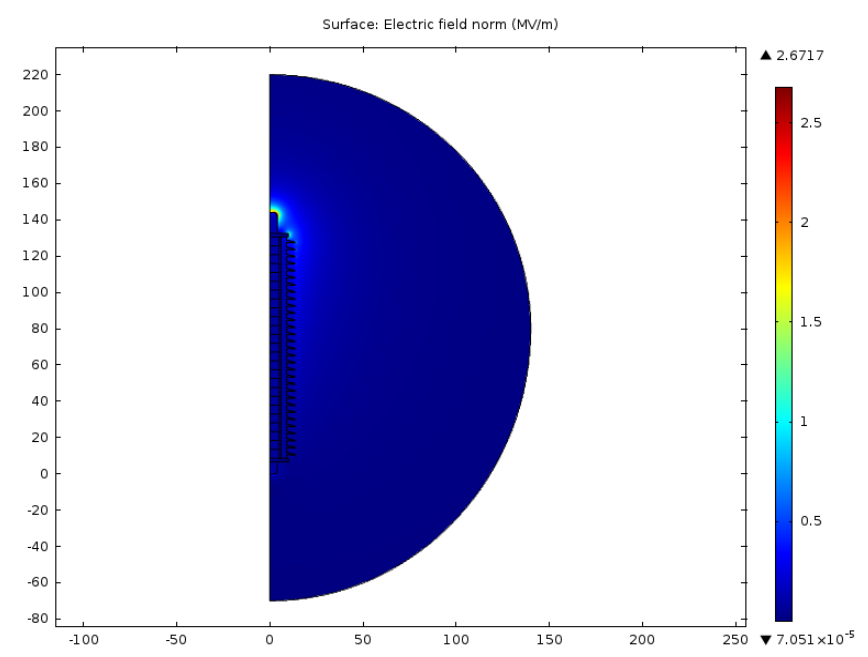

Figure 4. Electric field distribution of $120 \mathrm{kV}$ arrester

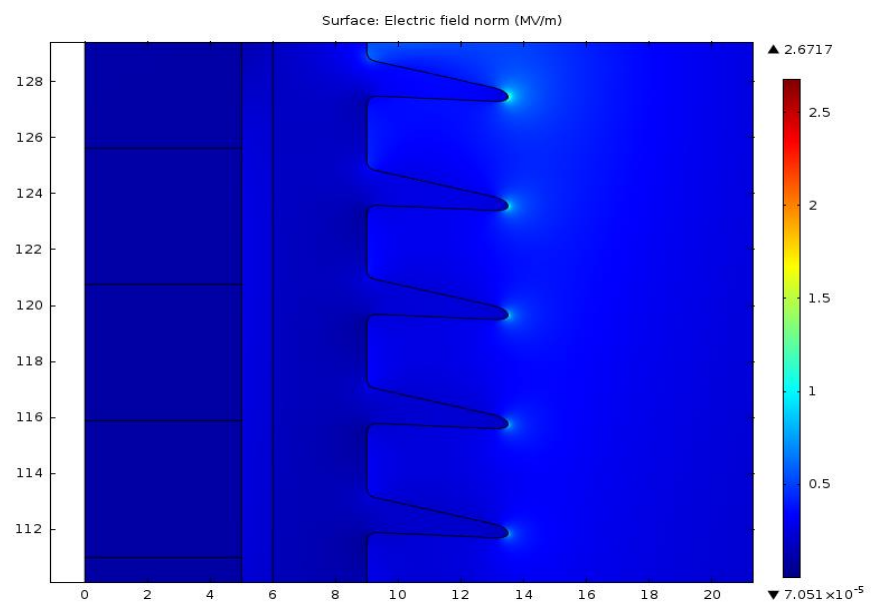

Figure 5. Electric field distribution on the tip of sheds

It is obvious that the electric field distribution along the sheds is not uniform where high magnitudes were observed mainly on the tip of the sheds which are nearer to energized end terminal. This is due to the different materials in the surge arrester's structure, which have different permittivity and boundary condition. Referring to Figure 6, the electric field magnitude also shows a sudden increase when there is a region transition from air to silicone rubber.

At the interface between air and the housing sheds, there is a discontinuity of the electric field due to the permittivity difference between both materials. The relative permittivity, $\varepsilon$, describes the ability of the material to align the electric field. A material with higher permittivity has higher ability to align the electric field, thus resulting in lower electric field concentration in the material. In this case, the relative permittivity of silicone rubber is normally higher than the air region. Therefore, the electric field between tips of the housing sheds and the air region is more intense than in the inner structure of the housing sheds. It is also observed that the electric field intensity decreases at the location further than the housing sheds, mainly in the region of air.

Table 4 presents the original and optimised parameters for FRP rod and silicone rubber housing materials of the $120 \mathrm{kV}$ surge arrester, calculated by the GSA and ICA methods. All optimized parameters were determined based on the evaluation of the minimum value of the objective function. The optimised dimension parameter values for the GSA algorithm only show slight deviations from the optimised values calculated by the ICA algorithm.

Table 5 presents the maximum electric field along the arrester axis obtained with original dimensions and optimised parameters of the $120 \mathrm{kV}$ surge arrester. It is obvious that the use of the optimised 
dimension and relative permittivity values of the FRP rod and the silicone rubber housing significantly reduces the maximum electric field on the tip of the housing shed, which is nearer to the energized end electrode. Implementing the optimised values from the ICA algorithm results in slightly lower electric field intensity compared to the GSA optimised values.

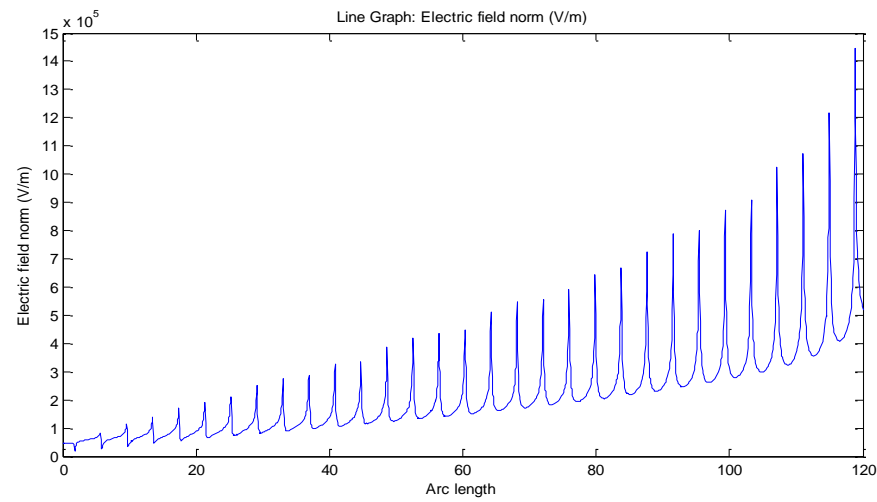

Figure 6. 2D cut line of electric field along the tip of sheds

Table 4. Initial And Optimised Design Parameters of the Arrester

\begin{tabular}{cccc}
\hline Parameter & \multicolumn{1}{c}{ Initial value } & GSA value & ICA value \\
\hline Radius of FRP rod $(\mathrm{cm})$ & 1.0 & 1.34 & 1.13 \\
Radius of insulation housing $(\mathrm{cm})$ & 3.0 & 2.07 & 2.37 \\
Permittivity of FRP rod & 4.2 & 9.52 & 7.96 \\
Permittivity of silicone rubber & 6.0 & 6.69 & 6.71 \\
\hline
\end{tabular}

Table 5. Maximum Electric Field Along the Arrester Axis

\begin{tabular}{|c|c|c|c|c|c|}
\hline \multirow{2}{*}{ Model } & \multicolumn{5}{|c|}{ Maximum electric field $\left(\mathrm{kVmm}^{-1}\right)$} \\
\hline & Initial value & GSA Optimised & Reduction using GSA & ICA Optimised & Reduction using ICA \\
\hline $120 \mathrm{kV}$ & 0.9838 & 0.2461 & $74.98 \%$ & 0.2452 & $75.08 \%$ \\
\hline
\end{tabular}

\section{COMPARISON WITH MANUFACTURER'S DATASHEET}

Further validation on the accuracy of the surge arrester model was made by comparing the estimated peak residual voltages with the manufacturer's data. The measured data for the residual voltages of the 120 $\mathrm{kV}$ surge arrester is $316 \mathrm{kV}$. For a $10 \mathrm{kA}$ nominal discharge current of $8 / 20 \mu \mathrm{s}$, the residual voltages obtained using the original dimension parameters and the optimised parameters show only slight deviations from the manufacturer's data. Relative errors of the discharge voltages for the $120 \mathrm{kV}$ arrester were then determined to evaluate the precision of the arrester's characteristics, calculated using:

$$
\text { error }=\frac{V_{r_{\text {estimated }}}-V_{r_{\text {manufacturer }}}}{V_{r_{\text {estimated }}}} \times 100 \%
$$

where $V r_{\text {estimated }}$ is the estimated discharge voltage and $V r_{\text {manufacturer }}$ is the voltage from the manufacturer's data.

As can be observed from Table 6, the use of the optimised parameter values in both surge arrester models reduce the relative errors between the estimated and manufacturer's data of the residual voltages. Furthermore, both optimised parameters obtained from GSA and ICA iteration method also reproduce the residual voltages of the $120 \mathrm{kV}$ arrester with low relative error. The good agreement between the estimated and actual measurement data has demonstrated that design optimisation by FEA model is a valid option for future arrester development.

Figure 7 shows the electric field distribution along the $120 \mathrm{kV}$ arrester sheds for original dimension parameters, GSA parameters and ICA parameters respectively. A minor reduction in the maximum electric field magnitude was observed from GSA and ICA due to the optimised thickness and relative permittivity values of the FRP layer and silicone rubber housing. Based on these figures, discontinuity of the electric field 
between the housing shed and the air domain was observed due to the difference in the permittivity value of silicone rubber and air. Comparison between the proposed method and a meta-heuristic optimisation method which is widely used, the particle swarm optimisation (PSO) was also made [12-15]. From Table 7, it can be seen that the optimisation methods using ICA and GSA yield lower minimum electric field magnitude than PSO. This shows that ICA and GSA are a better optimisation method compared to PSO. The features which make ICA and GSA are better than PSO are good convergence rate, high quality solution and capabilities in finding local optimum.

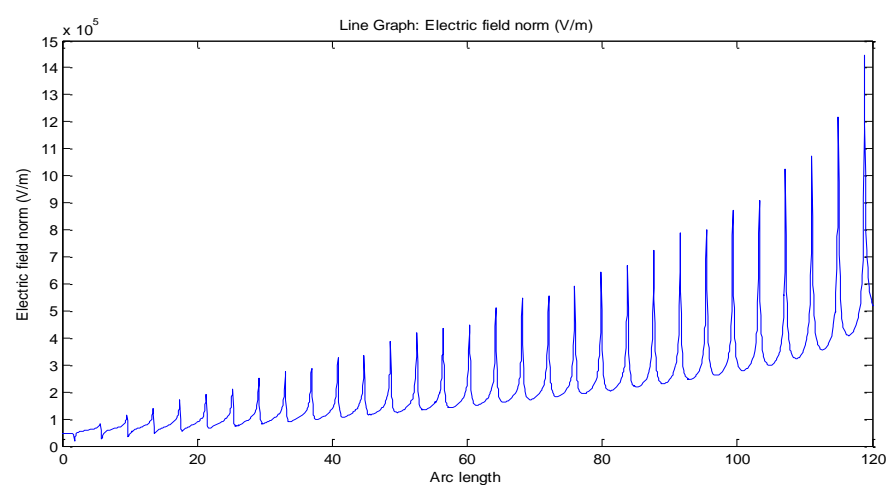

(a)

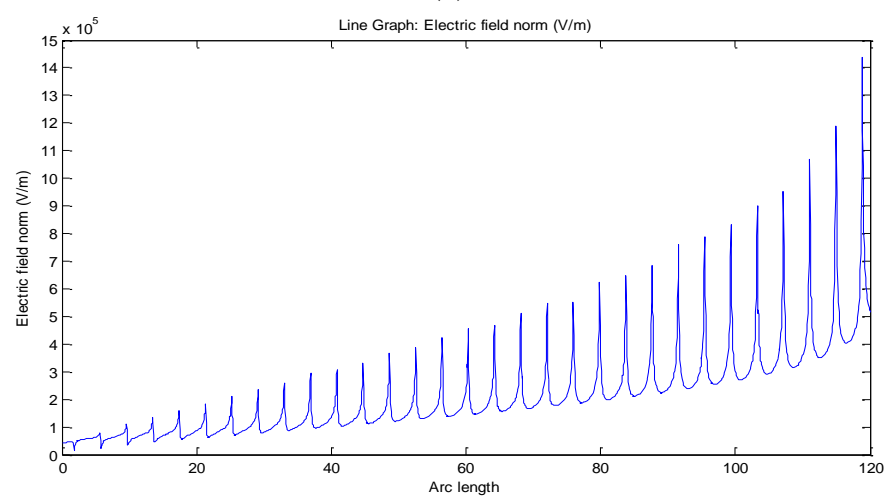

(b)

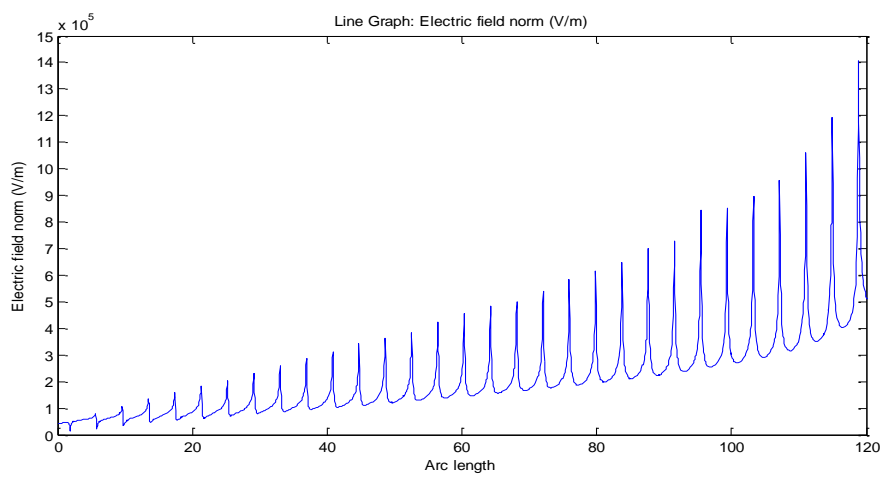

(c)

Figure 7. Electric field magnitude along the shed of $120 \mathrm{kV}$ arrester using; (a) original dimension parameters, (b) GSA parameters and (c) ICA parameters

Table 6. Relative Errors Between the Estimated and Manufacturer's Data

\begin{tabular}{ccccccc}
\hline \multirow{2}{*}{ Model } & \multicolumn{3}{c}{ Residual voltage $(\mathrm{kV})$} & \multicolumn{3}{c}{ Relative error to manufacturer's data (\%) } \\
\cline { 2 - 6 } & Initial & GSA & ICA & Inital & GSA & ICA \\
\hline $120 \mathrm{kV}$ & 317.35 & 317.28 & 317.32 & 0.42 & 0.40 & 0.41 \\
\hline
\end{tabular}


Table 7. Minimum Electric Field Obtained from Initial and Optimized Parameters

\begin{tabular}{ccccc}
\hline \multirow{2}{*}{ Model } & \multicolumn{4}{c}{ Minimum electric field $\left(\mathrm{kVmm}^{-1}\right)$} \\
\cline { 2 - 4 } & Initial value & GSA optimised & ICA optimised & PSO optimised \\
\hline $120 \mathrm{kV}$ & 0.983825 & 0.246130 & 0.245202 & 0.25656 \\
\hline
\end{tabular}

\section{CONCLUSION}

In this work, the optimisation of a $120 \mathrm{kV} \mathrm{ZnO}$ surge arrester design model using GSA and ICA has been successfully proposed. The surge arrester models were successfully developed using finite element analysis and used to determine the electric field distribution. By optimizing the relative permittivity and radius of the FRP rod and the silicone rubber housing, the electric field intensity surrounding the arrester has been successfully reduced while maintaining its physical properties. With optimised arrester dimensions, the lowest concentration of the electric field on the surface of the arrester insulation housing can be achieved, which in turn may increase the service life span of the surge arrester. Comparison of the proposed method shows that the optimised surge arrester design model complies with the manufacturer's test data and yields lower minimum electric field magnitude at the energized end of the surge arrester. It was also found that the minimum electric field is lower using ICA than GSA and PSO.

\section{ACKNOWLEDGEMENTS}

The authors would like to acknowledge Faculty of Engineering and Built Environment and Universiti Kebangsaan Malaysia for the facilities and financial supports through research grant code number GGPM-2018-056.

\section{REFERENCES}

[1] Lee SB, Lee SJ, Lee BH. Analysis of Thermal and Electrical Properties of ZnO Arrester Block. Current Applied Physics. 2010; 10(1): 176-180.

[2] Hosseini SA, Mirzaie M, Barforoshi T. Reliability Analysis of Surge Arrester Location Effect in High Voltage Substations. Indonesian Journal of Electrical Engineering and Computer Science. 2014; 12(8): 5814-5826.

[3] He JL, Zeng R, Chen SM, Guan ZC. Potential Distribution Analysis of Suspended-Type Metal-Oxide Surge Arrester's. IEEE Transactions on Power Delivery. 2003; 18(4): 1214-1220.

[4] Han SJ, Zou J, Gu SQ, He JL, Yuan JS. Calculation of The Potential Distribution of High Voltage Metal Oxide Arrester by Using an Improved Semi-Analytic Finite Element Method. IEEE Transactions on Magnetics. 2005; 41(5): 1392-1395.

[5] Haddad A, Naylor P. Finite-Element Computation of Capacitance Networks in Multiple-Electrode Systems: Application to $\mathrm{ZnO}$ Surge Arresters. IEEE Proceedings-Science Measurement and Technology. 1998; 145: 129135 .

[6] Ekonomou L, Christodoulou CA, Mladenov V. Estimation of the Electric Field Across Medium Voltage Surge Arresters Using Artificial Neural Networks. Engineering Applications of Neural Networks. 2014; 459: 227-236.

[7] Kumar U, Mogaveera V. Voltage Distribution Studies on ZnO Arresters. IEEE Proceedings-Generation Transmission and Distribution. 2002; 149(4): 457-462.

[8] Rashedi E, Nezamabadi PH, Saryazdi S. GSA: A Gravitational Search Algorithm. Information Sciences. 2009; 179(13): 2232-2248.

[9] Zamani MKM, Musirin I, Omar MS, Suliman SI, Ghani NA, Kamari NA. Gravitational search algorithm based technique for voltage stability improvement. Indonesian Journal of Electrical Engineering and Computer Science. 2018; 9(1): 123-130.

[10] Atashpaz-Gargari E, Lucas C. Imperialist Competitive Algorithm: An Algorithm for Optimization Inspired by Imperialistic Competition. IEEE Congress on Evolutionary Computation. 2007; 4661-4667.

[11] Xing B, Gao WJ. Innovative Computational Intelligence: A Rough Guide to 134 Clever Algorithms. Switzerland: Springer; 2014.

[12] Wahab MNA, Nefti-Meziani S, Atyabi A. A Comprehensive Review of Swarm Optimization Algorithms. Plos One. 2015; 10(5).

[13] Illias HA, Chai XR, Bakar AHA, Mokhlis H. Transformer Incipient Fault Prediction Using Combined Artificial Neural Network and Various Particle Swarm Optimisation Techniques. Plos One. 2015; 10(6).

[14] Liu C, Du WB, Wang WX. Particle Swarm Optimization with Scale-Free Interactions. Plos One. 2014; 9(5).

[15] Ali AM, Ebrahim MA, Hassan MM. Automatic voltage generation control for two area power system based on particle swarm optimization. Indonesian Journal of Electrical Engineering and Computer Science. 2016; 2(1): 132144. 